\title{
Trends in obesity prevalence among Brazilian adults from 2002 to 2013 by educational level
}

\author{
Danilo Cosme Klein Gomes ${ }^{1 *}$, Rosely Sichieri ${ }^{1}$, Eliseu Verly Junior ${ }^{1}$, Cristiano Siqueira Boccolini ${ }^{2}$, \\ Amanda de Moura Souza ${ }^{3}$ and Diana Barbosa Cunha ${ }^{1}$
}

\begin{abstract}
Background: Obesity ranks as a major public health problem in many countries in the world. The obesitysocioeconomic status relationship is not well established in middle-income countries.

Methods: The aim of this study was to estimate the obesity and overweight trends from 2002 to 2013 by sex, age, and educational levels among Brazilian adults. The panel prevalence trend study was conducted, considering the sample weights and study design. Three nationwide surveys were analyzed: the Household Budget Survey 2002/ 2003 and 2008/2009, and the National Health Survey 2013. The total sample was 234,791 adults aged 20-59 years.

Results: The prevalence of obesity increased from 7.5 to $17.0 \%$ from 2002 to 2013 among adults aged 20-39years and from 14.7 to $25.7 \%$ among those aged 40-59 years, slightly higher among young women. In each survey, education was positively associated with the prevalence of obesity among men, whereas this association was negative among women. The greatest increase in the prevalence of obesity was $90 \%$ (11.9 to 22.5\%) and occurred from 2008 to 2013 among women with secondary educational level, whereas at the pre-primary level there was a $42 \%$ (20.4 to $29.0 \%)$ increase.
\end{abstract}

Conclusions: Obesity prevalence in Brazil continued to increase, mostly among women with secondary education. Policies aimed at reducing the prevalence of obesity should consider sociodemographic characteristics in the population.

Keywords: Obesity, Overweight, Body mass index, Prevalence, Educational status

\section{Background}

Obesity is a risk factor for many chronic noncommunicable diseases and poses a great challenge to global and Brazilian health systems. More than $74 \%$ of all deaths in Brazil are attributed to chronic noncommunicable diseases [1], with less privileged groups bearing a large share of this burden [2]. From 1980 to 2010, the prevalence of diabetes in Brazil increased from 7.4 to 15.7\% [3].

The worldwide prevalence of obesity has nearly tripled since 1975. In 2016, 39\% of adults worldwide were overweight, and $13 \%$ were obese [4]. Although obesity is a

\footnotetext{
* Correspondence: danilocklein@gmail.com

${ }^{1}$ Institute of Social Medicine, State University of Rio de Janeiro, São Francisco Xavier, 524 - 7 andar, Bloco E, sala E-7017B, Maracanã, CEP, Rio de Janeiro, RJ 20550-900, Brazil

Full list of author information is available at the end of the article
}

multifactorial disease, environments that promote a higher energy intake have greatly influenced this epidemic [5].

Low and middle-income countries showed the greatest increase in the prevalence of obesity between 1975 and 2014, and will likely soon exceed the prevalence in developed countries. In 2014, Brazil, a middle-income country, was ranked third in the world for the absolute number of obese adult men (11.9 million), falling behind only China and the United States. The country also occupied the fifth position for the number of obese women (18.0 million) [6]. Also, socioeconomic status (SES) and obesity are positively associated in lower-income countries but negatively associated in higher-income countries $[7,8]$. However, the obesity-SES relationship is not well established in middleincome countries [9] where the prevalence may reach those of developing countries in the coming years [10]. In Brazil, telephone surveillance surveys showed an increase

(c) The Author(s). 2019 Open Access This article is distributed under the terms of the Creative Commons Attribution 4.0 International License (http://creativecommons.org/licenses/by/4.0/), which permits unrestricted use, distribution, and 
in the prevalence of obesity from 2006 to 2017, reaching $18.9 \%$ of adults in the last survey; that survey also showed an increase in the prevalence of obesity among women with lower educational level [11]. These telephone surveys in Brazil were limited by three factors. Only capitals were included, there was a lack of telephones in houses of the poorest population, and weight and height were selfreported. This was not the case in the national surveys included in the present study. Also, educational levels in Brazil showed greater improvement from 2002 to 2013. Secondary levels of education almost doubled in this period [12].

The identification of obesity trends in subgroups of the nationwide population may help to better plan specific prevention measures. Therefore, the purpose of this study was to analyze overweight and obesity trends according to sex, age, and educational levels in Brazilian adults.

\section{Methods}

Data from three nationally representative surveys were analyzed: the Household Budget Survey-Pesquisa de Orçamento Familiar (POF) conducted in 2002/2003 and 2008/2009, and the National Health Survey-Pesquisa Nacional de Saúde (PNS), undertaken in 2013. The Brazilian Institute of Geography and Statistics (IBGE) was responsible for the surveys. The raw data and questionnaires for data collection are publicly available [13-15].

The sampling procedures included multi-stage stratified clusters. In the first stage of the POFs, primary sampling units (PSUs) were selected by systematic sampling proportionally to the number of households. For the second stage, households were selected by simple random sampling without replacement. Anthropometric measurements were taken from all individuals present in the selected households at the time of the interview.

The PNS sample was a subsample of the Master Sample of the Integrated Household Surveys System of the Brazilian Institute of Geography and Statistics. Cluster sampling was performed in three stages: the PSUs comprised sectors of the census and were obtained by simple random sampling among those previously selected for the Master Sample. It maintained the PSU stratification used in the Master Sample. The secondary unit included 10 to 14 households selected from each PSU, and the third unit included one person aged 18 years or more from each household who responded to the individual component of the questionnaire distributed by the PNS.

The initial databases included 182,333, 190,159, and 205,546 individuals from the $2002 / 2003,2008 / 2009$, and 2013 surveys, respectively. This study analyzed data from adults between 20 and 59 years of age of both sexes. Pregnant women were excluded, resulting in a sample comprising 234,791 adults: 89,651 (2002/2003), 100,956 (2008/2009) and 44,184 (2013). Weight and height were measured similarly in all three surveys using portable digital scales and wall-mounted stadiometers. Trained interviewers performed all anthropometric measurements and individuals were asked to remove their shoes before measurements. The classification of nutritional status was based on body mass index (BMI). Overweight and obesity were defined as BMI between $25.0-29.9 \mathrm{~kg} /$ $\mathrm{m}^{2}$ and greater than $30 \mathrm{~kg} / \mathrm{m}^{2}$, respectively [16].

Data regarding education were collected in the POFs as years of education and as levels of education (in seven categories) in the PNS. In order to allow comparability between the surveys, harmonization was carried out following the International Standard Classification of Education: preprimary ( 0 to 7 years of study or incomplete primary school), primary ( 8 to 10 years of study, complete primary school or incomplete secondary school), secondary (11 to 14 years of study, complete secondary school or incomplete tertiary school) and tertiary (greater than 15 years of study, complete tertiary school or more) [17].

The prevalence (percentage) of overweight and obesity were estimated by sex, age group (20-39 and 40-59 years), and educational level (pre-primary, primary, secondary and tertiary). Logistic regression was used to evaluate trends in the prevalence of obesity and overweight. To account for the gaps between the surveys, we encoded the 2002/2003 survey as 2, the 2008/2009 survey as 8 , and the 2013 survey as 13 and used the 2002/ 2003 survey as the reference. All analyses were stratified by sex. Interactions of age group, educational level, and survey were assessed in order to test the effect modification in the prevalence of obesity trend by the educational level. Also, a logistic regression model was used to test the possibility of a cohort effect, including a cohort indicator variable with 4 categories $(1950,1960,1970$, and 1980). The variable outcome was obesity (yes/no) and this model was adjusted by age as a continuous variable. All analyses accounted for the sample weights and for the effect of the sample design, using SAS software version 9.4 (SAS Institute Inc., Cary, NC).

\section{Results}

From 2002 to 2013, the prevalence of overweight and obesity increased in both sexes and with age in all surveys. Among women, the prevalence of obesity was highest in all surveys for both age groups. Men had a higher prevalence of overweight and a lower prevalence of obesity compared to women in all surveys (Fig. 1).

Overall, the prevalence of obesity increased from $7.5 \%$ (7.0-7.9) to $17.0 \%$ (16.2-17.8) from 2002 to 2013 in adults aged $20-39$ years and from $14.7 \%(14.0-15.4)$ to $25.7 \%$ (24.5-26.9) among those aged $40-59$ years. The prevalence of obesity in the 20-39 year age group from 2002 to 2013, increased from $6.6 \%(6.0-7.1)$ to $14.0 \%(12.8-15.2)$ among men and $8.4 \%(7.8-9.0)$ to $19.9 \%(18.7-21.1)$ 

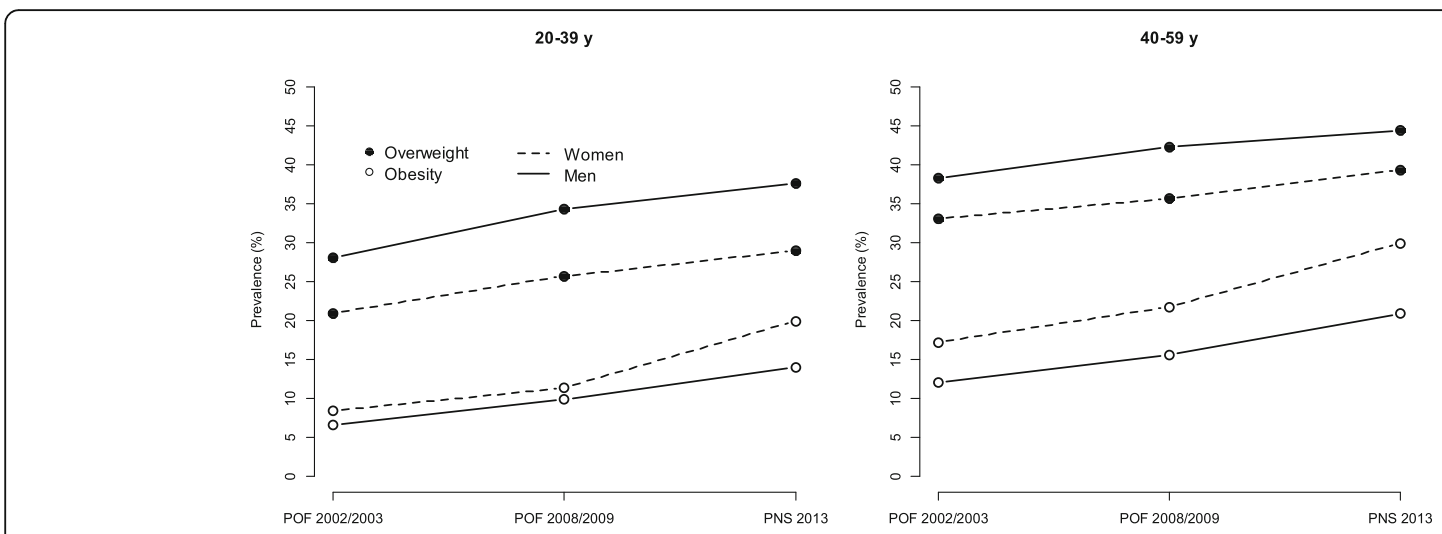

Fig. 1 Weighted prevalence of overweight and obesity among Brazilian adults by age group and sex. Brazil, 2002-2013. Note: POF, Pesquisa de Orçamento Familiar - Household Budget Survey; PNS, National Health Survey - Pesquisa Nacional de Saúde

among women; in the $40-59$ year age group in the same period, the prevalence of obesity increased from $12.0 \%$ (11.1$12.9)$ to $20.9 \%(19.3-22.5)$ among men and from $17.2 \%$ (16.3-18.1) to $29.9 \%$ (28.3-31.5) among women (Fig. 1).

Figure 1 also indicates a cohort effect since the prevalence of obesity in the lower category of age in 2013 was higher than that in the older group at the beginning of the period, which was confirmed in the logistic regression models $(p<0.05)$.

There was an increase in the proportion of individuals with the highest educational levels in both sexes from
2002 to 2013. For both sexes, the greater changes in the educational level occurred at the tertiary level between 2002 and 2013 and at the secondary level between 2008 and 2013 (Table 1).

The prevalence of overweight and obesity increased over time for all educational levels and sex. In 2013, the highest prevalence of obesity was at the tertiary level among men $(22.1 \%)$ and at the pre-primary level among women $(29.0 \%)$, while the highest prevalence of overweight was at the tertiary level among men (46.8\%) and at the pre-primary level among women (37.3\%). The

Table 1 Sample size (n) and percentage (\%) by sex and educational level, weighted prevalence and 95\% confidence interval of overweight and obesity among Brazilian adults according to educational level and sex. Brazil, 2002-2013

\begin{tabular}{|c|c|c|c|c|c|c|c|c|c|c|}
\hline \multirow{3}{*}{ Schooling } & & \multicolumn{3}{|c|}{ POF 2002/2003 } & \multicolumn{3}{|c|}{ POF 2008/2009 } & \multicolumn{3}{|c|}{ PNS 2013} \\
\hline & & Sample & Overweight & Obesity & Sample & Overweight & Obesity & Sample & Overweight & Obesity \\
\hline & & $\mathrm{n} \%$ & $\begin{array}{l}\text { Prevalence } \\
95 \% \mathrm{Cl}\end{array}$ & $\begin{array}{l}\text { Prevalence } \\
95 \% \mathrm{Cl}\end{array}$ & n \% & $\begin{array}{l}\text { Prevalence } \\
95 \% \mathrm{Cl}\end{array}$ & $\begin{array}{l}\text { Prevalence } \\
95 \% \mathrm{Cl}\end{array}$ & n \% & $\begin{array}{l}\text { Prevalence } \\
95 \% \mathrm{Cl}\end{array}$ & $\begin{array}{l}\text { Prevalence } \\
95 \% \mathrm{Cl}\end{array}$ \\
\hline \multirow[t]{8}{*}{ Men } & Pre-primary & 26,576 & 29.4 & 8.1 & 24,104 & 35.1 & 11.3 & 7,001 & 37.9 & 15.1 \\
\hline & & 59.3 & $28.4-30.4$ & $7.5-8.8$ & 48.7 & $34.2-36.0$ & $10.6-12.0$ & 36.1 & $35.9-39.9$ & $13.6-16.6$ \\
\hline & Primary & 6,973 & 33.4 & 8.0 & 7,893 & 37.6 & 11.9 & 3,100 & 36.6 & 16.3 \\
\hline & & 15.6 & $31.4-35.4$ & $7.0-9.1$ & 16.0 & $35.9-39.3$ & $10.7-13.3$ & 16.0 & $34.0-39.2$ & $13.9-18.8$ \\
\hline & Secondary & 8,429 & 34.4 & 9.0 & 13,848 & 38.6 & 13.0 & 6,770 & 43.4 & 17.2 \\
\hline & & 18.8 & $32.5-36.2$ & $7.9-10.1$ & 28.1 & $37.3-39.9$ & $12.6-14.5$ & 34.9 & $41.4-45.4$ & $15.7-18.9$ \\
\hline & Tertiary & 2,846 & 40.2 & 11.8 & 3,571 & 45.5 & 13.0 & 2,529 & 46.8 & 22.1 \\
\hline & & 6.3 & $37.2-43.3$ & $9.9-14.1$ & 7.2 & $43.1-48.1$ & $11.6-14.6$ & 13.0 & $43.6-49.9$ & $19.5-24.9$ \\
\hline \multirow[t]{8}{*}{ Women } & Pre-primary & 24.296 & 29.7 & 15.1 & 22,552 & 33.6 & 20.4 & 7,979 & 37.3 & 29.0 \\
\hline & & 54.2 & 28.7-30.7 & $14.3-15.9$ & 43.8 & $32.6-34.5$ & $19.6-21.2$ & 32.2 & $35.4-39.3$ & $27.3-30.8$ \\
\hline & Primary & 6,829 & 24.4 & 9.9 & 7,709 & 29.9 & 15.0 & 3,854 & 36.4 & 25.1 \\
\hline & & 15.2 & $22.5-26.3$ & $8.7-11.2$ & 15.0 & $28.3-31.4$ & $13.8-16.2$ & 15.5 & $33.7-39.1$ & $22.8-27.5$ \\
\hline & Secondary & 10,092 & 21.1 & 7.5 & 16,243 & 26.9 & 11.9 & 9,209 & 32.0 & 22.5 \\
\hline & & 22.5 & $19.7-22.5$ & $6.7-8.5$ & 31.5 & $25.9-27.9$ & $11.1-12.8$ & 37.2 & $30.4-33.7$ & $21.0-24.2$ \\
\hline & Tertiary & 3,610 & 20.2 & 9.5 & 5,036 & 25.4 & 12.2 & 3,742 & 29.4 & 18.5 \\
\hline & & 8.1 & $17.6-22.7$ & 7.6-11.7 & 9.7 & $23.5-27.0$ & $10.8-13.7$ & 15.1 & $27.4-31.7$ & $16.1-21.0$ \\
\hline
\end{tabular}

Note: POF, Pesquisa de Orçamento Familiar - Household Budget Survey; PNS, National Health Survey - Pesquisa Nacional de Saúde; n, number; Cl, confidence interval. Age-Adjusted Prevalence 
greater of changes in the prevalence of obesity occurred between 2008 and 2013 among women at the secondary level (11.9 to 22.5\%). The highest educational levels had the highest prevalence of overweight and obesity for men and the lowest for women; this suggests a negative relationship between educational level and obesity in women and a positive one in men (Table 1).

Overall, for both age groups the odds of being obese doubled in 2013 compared to those in 2002, while the chance of being overweight increased by almost 1.5 times in both sexes in the same period. Young women had the highest chance of becoming obese (Table 2).

In 2002 and 2008, women with tertiary and secondary educational levels had lower prevalence of overweight and obesity (Table 1); however, from 2008 to 2013, the rate of change of the prevalence of obesity was higher among women with secondary educational level compared to those with low education, as indicated by the statistically significant effect modification of survey observed in Fig. 2. The interaction term, which measured the change in time differences among women, had $p$ values lower than 0.05 for women.

\section{Discussion}

This study reveals a significant increase in the prevalence of overweight and obesity in the adult Brazilian population from 2002 to 2013, mainly among women. Educational level improved in this period and the proportion of people of both sexes at the highest level almost doubled from 2002 to 2013. The changes in the prevalence of overweight and obesity were not homogeneous by educational level and sex. A greater rate of change occurred among women with secondary educational level, whereas men at all educational levels had a similar increase in the prevalence of obesity.

Although obesity is a problem faced by almost all countries $[7,18,19]$, the prevalence varies by sex as well as by socioeconomic level [20]. In European countries, the differences according to sex are small, whereas women in the United States, Mexico, Fiji Island, South Africa, and Brazil are at greater risk of obesity compared to men [6]. A systematic review in 2004 identified a shift towards poor women in developing countries i.e. an increase in obesity prevalence amongst poor women in developing countries [20].

In contrast with our findings, studies from highincome countries have shown a negative association between educational level and obesity in both sexes $[9,18$, $21,22]$, with women being more influenced by the educational level [18, 22].

Similar to our results, a 2011-2014 survey conducted in the United States showed a higher prevalence of obesity among women than among men, and an even higher prevalence of it among the less educated women [23]. In medium-income countries, a positive association between obesity rate and educational level has been observed, while this association tends to be negative in high-income countries [24]. Our data indicate that Brazil has a more complex situation: the prevalence among women is negatively associated with increased education and lower rates of obesity among those with higher educational levels, while men had higher rates of obesity with higher educational levels, similar to the poorest countries. Also, the trend over decades is changing. In a previous study conducted in Brazil, the prevalence of obesity increased among men from 1989 to 2003. The increases were greater among the poor, but the obesity rate remained stable among women [25]. The more recent population-based data used in our analysis also shows a negative association between obesity and educational level in women and a positive association in men. The movement of women from the pre-primary and primary educational level to the secondary educational level sub-population due to many successful public policies aimed at increasing education in Brazil [26, 27] is likely to explain the greater increase in the prevalence of overweight and obesity among women with a secondary level of education. Moreover, the characteristics of the women

Table 2 Odds ratio (OR) and 95\% confidence intervals for obesity and overweight trend among Brazilian adults compared to 2002/ 2003

\begin{tabular}{|c|c|c|c|c|c|c|}
\hline & & \multirow[b]{2}{*}{ Age } & \multicolumn{2}{|c|}{$2008 / 2009$} & \multicolumn{2}{|c|}{2013} \\
\hline & & & OR & 95\% confidence interval & OR & 95\% confidence interval \\
\hline \multirow[t]{4}{*}{ Obesity } & Men & $20-39$ & 1.5 & $1.4-1.7$ & 2.2 & $1.9-2.5$ \\
\hline & & $40-59$ & 1.4 & $1.2-1.5$ & 1.8 & $1.6-2.0$ \\
\hline & Women & 20-39 & 1.4 & $1.2-1.5$ & 2.5 & $2.3-2.8$ \\
\hline & & $40-59$ & 1.3 & $1.2-1.5$ & 1.9 & $1.7-2.0$ \\
\hline \multirow[t]{4}{*}{ Overweight } & Men & $20-39$ & 1.3 & $1.2-1.4$ & 1.4 & $1.3-1.5$ \\
\hline & & $40-59$ & 1.2 & $1.0-1.3$ & 1.2 & $1.0-1.3$ \\
\hline & Women & $20-39$ & 1.3 & $1.2-1.4$ & 1.4 & $1.3-1.5$ \\
\hline & & $40-59$ & 1.1 & $1.0-1.2$ & 1.2 & $1.1-1.3$ \\
\hline
\end{tabular}




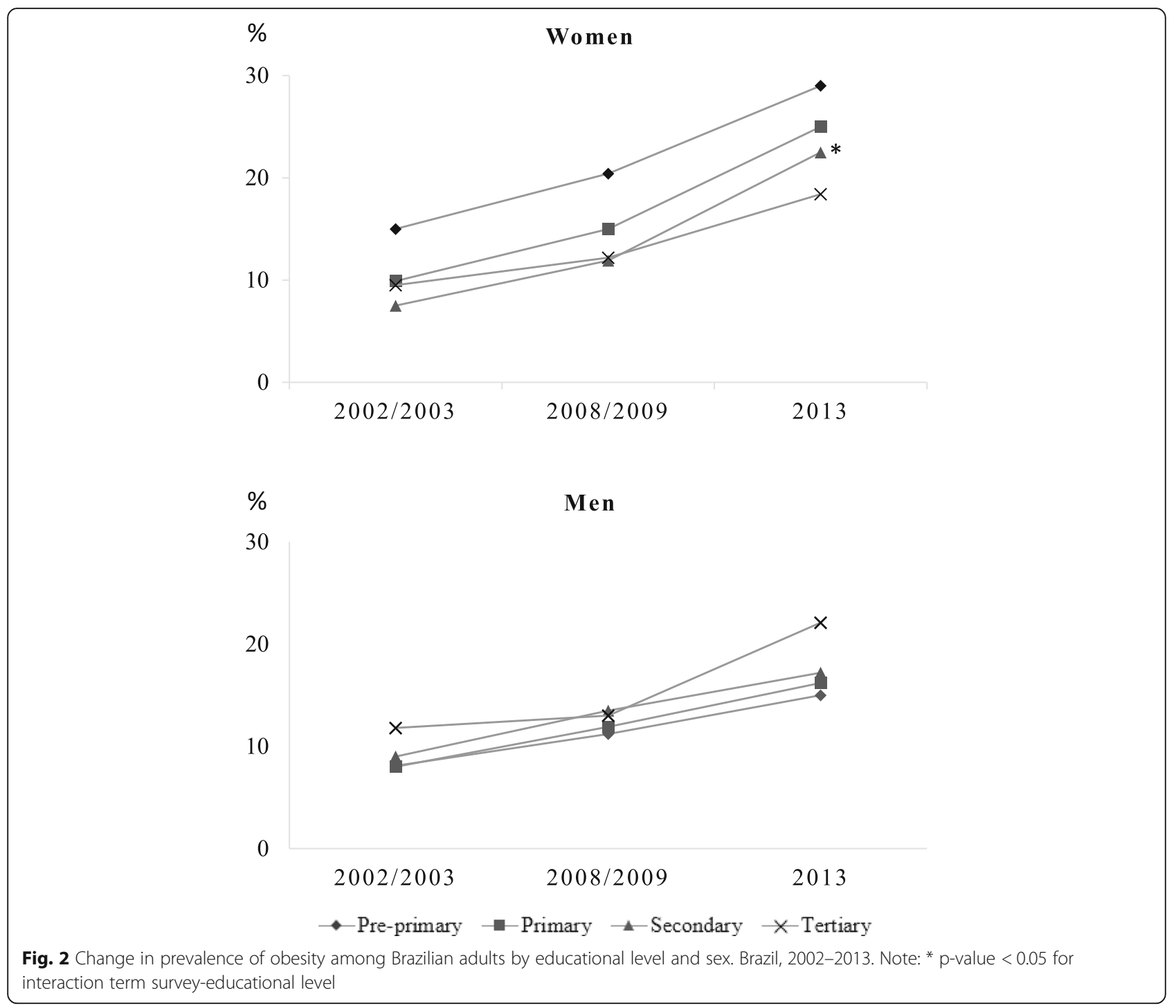

in the secondary educational group have probably changed, including more poor/rural women. However, there was a clear graded association between level of education and prevalence of overweight and obesity in both sexes. Similar to our findings, a recent Swedish study showed that the most important increase in prevalence of obesity occurred at the middle educational level [28].

We also identified a cohort effect for both sexes. The increase in energy intake and the decrease in energy expenditure over the last decades is the hypothesis for the birth cohort effect found in our study [29]. One limitation of this consideration is that the subpopulation at the secondary school level in 2013 was likely different from the subpopulation at the secondary level in 2002 i.e. poorer children are more likely to access a higher level of education in the later cohorts [30].
Our study has several strengths. The three national surveys of adults in Brazil used the same anthropometric measurements, the same resources and field worker training and similar sampling methodologies.

A possible weakness is the use of BMI instead of body fat, that may have changed across decades [31, 32]. However, in Brazil, BMI and body fat are strongly correlated [33]. Another limitation is that the questionnaire for capturing educational level was similar among POFs, but different from those used in the PNS.

The increased prevalence of overweight and obesity in the last decade among Brazilian adults observed in this study has important implications for public health due to their association with chronic medical conditions and to the high morbidity and mortality related to obesity [32] in addition to public health costs. The estimated total annual public cost associated with overweight and obesity-related diseases in Brazil was US\$ 2.1 billion [34]. 


\section{Conclusions}

This study shows an increase in the prevalence of obesity in the last decade among Brazilian adults of both sexes and at all levels of education. The highest educational levels had the highest prevalence of obesity and overweight for men and the lowest for women, and the increase in the prevalence of obesity among women occurred more prominently at the secondary educational levels. This may be due to changes in average levels of educational attainment throughout the study period. These findings reveal the need for nutritional education campaigns and policies to curb the obesity epidemic, since the recent educational improvements during this period coursed with cohort effect and less than the expected educational effect in the obesity prevalence.

\section{Abbreviations}

BMI: Body mass index; Cl: Confidence interval; IBGE: Brazilian Institute of Geography and Statistics; OR: Odds ratio; PNS: Pesquisa Nacional de Saúde National Health Survey; POF: Pesquisa de Orçamento Familiar - Household Budget Survey; PSU: Primary sampling units; SES: Socioeconomic status

\section{Acknowledgements}

No acknowledgments.

\section{Authors' contributions}

RS and DBC coordinated the study. DCKG, DBC and RS wrote the manuscript. DCKG, DBC, EVJ and CSB performed the statistical analysis. AMS, $\mathrm{RS}$ and $\mathrm{DBC}$ revised the manuscript. All authors have read and approved the final manuscript. All authors contributed.

\section{Funding}

No financial support.

\section{Availability of data and materials}

Details about each survey (data and questionnaires for data collection) can be found at https://ww2.ibge.gov.br/home/estatistica/populacao/ condicaodevida/pof/2002/default.shtm for POF 2002/03, https://ww2.ibge.gov.br/home/estatistica/populacao/condicaodevida/pof/2 008_2009/for POF 2008/09 and https://ww2.ibge.gov.br/home/estatistica/ populacao/pns/2013/default.shtm for PNS 2013.

\section{Ethics approval and consent to participate}

POF 2002/2003: All ethical related questions are in conformity with the Brazilian Resolution Number 196/96 (in accordance with the Brazilian law no. 5534); POF 2008/2009: The research protocol was reviewed and approved by the Ethics Committee of the Institute of Social Medicine of the Rio de Janeiro State University (CAAE 0011.0.259.000-11) in accordance with the Brazilian law no. 5534; PNS 2013: The National Commission of Ethics in Research (CONEP) approved the PNS project on June 26, 2013 (Regulation number 328.159). The informed consent obtained was written and all respondents have agreed to take part in the research and signed a free informed consent form.

\section{Consent for publication}

Not applicable.

\section{Competing interests}

The authors declare that they have no competing interests.

\section{Author details}

${ }^{1}$ Institute of Social Medicine, State University of Rio de Janeiro, São Francisco Xavier, 524 - 7 andar, Bloco E, sala E-7017B, Maracanã, CEP, Rio de Janeiro, RJ 20550-900, Brazil. ${ }^{2}$ Institute of Scientific and Technological Communication and Information in Health, Oswaldo Cruz Foundation, Rio de Janeiro, RJ, Brazil. ${ }^{3}$ Institute for Studies in Collective Health, Federal University of Rio de Janeiro, Rio de Janeiro, RJ, Brazil.
Received: 20 September 2018 Accepted: 9 July 2019

Published online: 18 July 2019

\section{References}

1. WHO. Noncommunicable diseases country profiles 2018. 2018.

2. Inês Schmidt M, Bartholow DB. O enfrentamento das doenças crônicas não transmissíveis: um desafio para a sociedade brasileira. Epidemiol e Serviços Saúde. 2011;20:421-3. https://doi.org/10.5123/S1679-49742011000400001.

3. Telo GH, Cureau FV, De SMS, Andrade TS, Copês F, Schaan BD. Prevalence of diabetes in Brazil over time : a systematic review with meta - analysis. Diabetol Metab Syndr. 2016:1-13.

4. WHO. Obesity and overweight. World Health Organisation. 2018. http:// www.who.int/mediacentre/factsheets/fs311/en/. Accessed 28 Nov 2018

5. Ezzati M, Riboli E. Behavioral and dietary risk factors for noncommunicable diseases. N Engl J Med. 2013:369:954-64. https://doi.org/10.1056/NEJMra1203528.

6. Di Cesare M, Bentham J, Stevens GA, Zhou B, Danaei G, Lu Y, et al. Trends in adult body-mass index in 200 countries from 1975 to 2014: A pooled analysis of 1698 population-based measurement studies with 19.2 million participants. Lancet. 2016;387:1377-1396. doi:https://doi.org/10.1016/S0140-6 736(16)30054-X

7. Kanter R, Caballero B. Global Gender Disparities in Obesity : A Review 1. Adv Nutr. 2012:491-8.

8. Jeffery RW, Utter J. The changing environment and population obesity in the United States. Obes Res. 2003;11 Suppl October:12S-22S. doi:https://doi. org/10.1038/oby.2003.221.

9. Dinsa GD, Goryakin Y, Fumagalli E, Suhrcke M. Obesity and socioeconomic status in developing countries: a systematic review. Obes Rev. 2012;13: 1067-79.

10. Bhurosy T, Jeewon R. Overweight and obesity epidemic in developing countries: a problem with diet, physical activity, or socioeconomic status? Sci World J. 2014;2014:964236. https://doi.org/10.1155/2014/964236.

11. Ministério da Saúde. Vigilância de fatores de risco e proteção para doenças crônicas por inquérito telefônico : estimativas sobre frequência e distribuição sociodemográfica de fatores de risco e proteção para doenças crônicas nas capitais dos 26 estados brasilei. Brasília; 2017.

12. Beltrán-Sánchez $H$, Andrade FCD. Time trends in adult chronic disease inequalities by education in Brazil: 1998-2013. Int J Equity Health. 2016;15: 139. https://doi.org/10.1186/s12939-016-0426-5.

13. IBGE. Instituto Brasileiro de Geografia e Estatística. Consumer Expenditure Survey 2002-2003. https://ww2.ibge.gov.br/english/xml/pof_2002_2003. shtm. Accessed 28 Nov 2018.

14. IBGE. Instituto Brasileiro de Geografia e Estatística. Consumer Expenditure Survey 2008-2009. https://ww2.ibge.gov.br/english/xml/pof_2008_2009. shtm. Accessed 28 Nov 2018.

15. IBGE. Instituto Brasileiro de Geografia e Estatística. National Survey of Health 2013. https://ww2.ibge.gov.br/english/estatistica/populacao/pns/2013/ default.shtm. Accessed 28 Nov 2018.

16. World Health Organization. Physical status: the use and interpretation of anthropometry. 1995.

17. UNESCO. The International Standard Classification of Education ISCED 2011 2012.

18. Devaux M, Sassi F, Church J, Cecchini M, Borgonovi F. Exploring the relationship between education and obesity. OECD J Econ Stud. 2011;2011: 121-59.

19. Ng M, Fleming T, Robinson M, Thomson B, Graetz N, Margono C, et al. Global, regional, and national prevalence of overweight and obesity in children and adults during 1980-2013: a systematic analysis for the global burden of disease study 2013. Lancet. 2014;384:766-81.

20. Monteiro CA, Moura EC, Conde WL, Popkin BM. Socioeconomic status and obesity in adult populations of developing countries: a review. Bull World Health Organ. 2004;82:940-6.

21. Großschädl F, Stronegger WJ. Long-term trends in obesity among Austrian adults and its relation with the social gradient: 1973-2007. Eur J Pub Health. 2012:23:306-12.

22. Molarius A, Seidell JC, Sans S, Tuomilehto J, Kuulasmaa K. Educational level, relative body weight, and changes in their association over 10 years: an international perspective from the WHO MONICA project. Am J Public Health. 2000;90:1260-8.

23. Flegal KM, Kruszon-Moran D, Carroll MD, Fryar CD, Ogden CL. Trends in obesity among adults in the United States, 2005 to 2014. Jama. 2016:315: 2284-91. https://doi.org/10.1001/jama.2016.6458. 
24. Cohen AK, Rai M, Rehkopf DH, Abrams B. Educational attainment and obesity : a systematic review. Obes Rev. 2014;14:989-1005.

25. Monteiro CA, Conde WL, Popkin BM. Income-specific trends in obesity in Brazil: 1975-2003. Am J Public Health. 2007;97:1808-12.

26. IBGE. Educação 2017 PNAD contínua 2018.

27. Inter-American Development Bank (IDB); IDB Invest; Multilateral Investment Fund. Development Effectiveness Overview (DEO) 2018. 2018.

28. Molarius A, Lindén-Boström M, Granström F, Karlsson J. Obesity continues to increase in the majority of the population in mid-Sweden - a 12-year follow-up. Eur J Pub Health. 2016;26:622-7.

29. Australian Institute of Health and Welfare. Overweight and obesity in Australia: a birth cohort analysis. Camberra; 2017.

30. Flegal KM, Pamuk ER. Interpreting trends estimated from national survey data. Prev Med (Baltim). 2007:45:115-6.

31. Flegal KM, Graubard BI. Estimates of excess deaths associated with body mass index and other athropometric variables. Am J Clin Nutr. 2009;89:1213-9.

32. MacMahon S, Baigent C, Duffy S, Rodgers A, Tominaga S, Chambless L, et al. Body-mass index and cause-specific mortality in 900000 adults: collaborative analyses of 57 prospective studies. Lancet. 2009;373:1083-96.

33. Sampaio LR, Figueiredo VDC. Correlation between body mass index and body fat distribution anthropometric indices in adults and the elderly. Rev Nutr. 2005:18:53-61.

34. Bahia L, Coutinho ES, Barufaldi LA, Abreu Gde A, Malhão TA, de SCPR, et al. The costs of overweight and obesity-related diseases in the Brazilian public health system: cross-sectional study BMC Public Health. 2012;12:1-7. https:// doi.org/10.1186/1471-2458-12-440.

\section{Publisher's Note}

Springer Nature remains neutral with regard to jurisdictional claims in published maps and institutional affiliations.

Ready to submit your research? Choose BMC and benefit from:

- fast, convenient online submission

- thorough peer review by experienced researchers in your field

- rapid publication on acceptance

- support for research data, including large and complex data types

- gold Open Access which fosters wider collaboration and increased citations

- maximum visibility for your research: over $100 \mathrm{M}$ website views per year

At $\mathrm{BMC}$, research is always in progress.

Learn more biomedcentral.com/submissions 